\title{
PENGARUH INTENSITAS CAHAYA DAN JARAK PADA SISTEM AUGMENTED REALITY OBJEK ANIMASI
}

\author{
Rudy Kustijono ${ }^{1}$, Septian Rahman Hakim ${ }^{2}$ \\ ${ }^{1)}$ Jurusan Fisika FMIPA Universitas Negeri Surabaya \\ ${ }^{2)}$ Prodi Pendidikan Teknologi Kejuruan PPs Universitas Negeri Surabaya \\ email : rudyunesa@gmail.com
}

\begin{abstract}
Abstrak
Telah dilakukan penelitian tentang pengaruh intensitas cahaya dan jarak pada sistem Augmented Reality objek animasi. Augmented Reality (AR) merupakan upaya untuk menggabungkan dunia maya (virtual) dan dunia nyata (real) yang dibuat melalui komputer sehingga batas antara keduanya menjadi sangat tipis. Untuk mengembangkan AR banyak sekali library pendukung yang dapat digunakan. FlarToolKit adalah salah satunya. FlarToolKit merupakan library pendukung AR pada platform flash. Dalam penelitian ini dibuatlah sistem AR objek animasi. Sistem yang dibuat dalam objek adalah permainan pingpong. Pada permainan pingpong disini berbeda pada permainan pingpong lainnya dimana telah dikolaborasikan dengan AR untuk menggerakkan setiap langkah dari playernya. Gerak setiap langkah tersebut dibantu dengan alat dengan nama marker pada saat proses rendering yang dilakukan kamera. Marker yang telah diregistrasi dapat dikenali dengan kamera dan dapat berinteraksi dengan objek bola dan komputer. Interaksi antar obyek tersebut dapat dilihat dari gerak bola yang dapat dipukul dengan ojyek virtual yang ditampilkan melalui AR. Hasil penelitian menunjukkan bahwa pembacaan marker oleh kamera sangat dipengaruhi oleh besarnya Intensitas cahaya. Untuk intensitas cahaya sedang (cahaya lampu) dapat menampilkan obyek virtual. Sedangkan intensitas cahaya yang terlalu kecil (gelap) dan intensitas cahaya yang terlalu besar (cahaya matahari), objek virtual tidak terlihat. Selain intensitas cahaya, jarak marker dengan kamera juga sangat berpengaruh dalam proses berjalannya sistem ini dimana marker yang telah dibaca oleh kamera ini nantinya akan di bandingkan dengan data marker yang menjadi acuannya. Bila terlalu dekat atau terlalu jauh maka kamera tidak dapat membaca marker dengan baik sehingga sistem tidak dapat mengenali marker tersebut. Jarak terdekat untuk marker terhadap kamera yang bisa menampilkan objek virtual adalah $10 \mathrm{~cm}$. Sedangkan jarak terjauh yang tidak bisa menampilkan objek adalah 1 meter.
\end{abstract}

Kata kunci : Augmented Reality, Animasi, Marker, FlarToolKit. 


\section{PENDAHULUAN}

Augmented Reality merupakan upaya untuk menggabungkan dunia nyata (real) dan dunia maya (virtual) yang dibuat melalui komputer sehingga batas antara keduanya menjadi sangat tipis. Augmented reality sebenarnya bukan teknologi baru. Teknologi ini telah ada setelah diperkenalkan aplikasi Virtual Reality. Pada saat itu, penelitian teknologi yang dilakukan ditujukan untuk aspek hardware. Head-Mounted Display (HMD) yang merupakan contoh hasil dari penelitian tentang Augmented Reality pada saat itu, dan merupakan satu-satunya peralatan dasar dalam teknologi terbaru. Seiring berjalannya waktu, Augmented Reality berkembang sangat pesat sehingga memungkinkan pengembangan aplikasi ini di berbagai bidang pendidikan [1]

Ronald Azzuma pada tahun 1997 [2] mendefinisikan Augmented Reality sebagai sistem yang memiliki karakter-karakter sebagai berikut :

- Menggabungkan lingkungan nyata dan virtual

- Berjalan secara Interaktif dalam waktu nyata

- Integrasi dalam tiga dimensi (3D)

Secara sederhana Augmented Reality bisa didefinisikan sebagai lingkungan nyata yang ditambahkan obyek virtual. Penggabungan obyek nyata dan virtual dimungkinkan dengan teknologi display yang sesuai, interaktvitas dimungkinkan melalui perangkat-perangkat input tertentu [3].

Augmented Reality saat ini telah dimanfaatkan ke banyak aspek di dalam kehidupan kita sehari-hari dan dimasa mendatang diprediksi akan mengalami perkembangan yang sangat berarti. Alasan yang relevan penggunaan augmented reality karena sangat menarik dan mudah penggunanya, misalnya ketika diterapkan pada objek animasi. Ketika ada objek animasi, bisanya hanya ditampilkan di dalam monitor saja sehingga tidak tampak nyata (virtual). Augmented Reality merupakan salah satu cara untuk menubah objek animasi akan terlihat nyata (real). Objek animasi yang terlihat nyata tersebut akan lebih mengembangkan imajinasi orang yang melihatnya.

\section{Augmented Reality}

Sistem Augmented Reality bekerja berdasarkan deteksi citra dan citra yang digunakan adalah marker. Prinsip kerjanya, webcam yang telah dikalibrasi akan mendeteksi marker yang diberikan, kemudian setelah mengenali dan menandai pola marker, webcam akan melakukan perhitungan apakah marker sesuai dengan database yang dimiliki. Bila tidak, maka informasi marker tidak akan diolah, tetapi bila sesuai maka informasi marker akan digunakan untuk merender dan menampilkan objek 3D atau animasi yang telah dibuat sebelumnya. Tahapan utama sistem Augmented Reality tersebut adalah sebagai berikut:

Langkah awal terlebih dahulu dibuat objek yang akan ditampilkan. Secara umum objek yang dibuat adalah benda 3D, foto, video, ataupun animasi yang dibuat dengan software perancangan objek seperti Google sketchup, 3DMax , atau dengan Blender.

Setelah objek jadi, maka objek tersebut akan disimpan ke dalam library. Kemudian setelah itu yang perlu dibuat adalah marker. Marker adalah sebuah penanda yang memiliki pola khusus. Marker yang digunakan untuk teknologi Augmented reality ini adalah pola kotak dengan standard tertentu. Marker inilah yang nantinya akan dideteksi oleh webcam untuk menampilkan objek. Setelah itu pola marker yang dibuat harus disimpan ke dalam library juga agar nantinya aplikasi yang dibuat dapat membedakannya dengan marker yang lain. Biasanya penyimpanan marker ini membutuhkan bantuan aplikasi lain seperti marker generator. 
Kedua komponen utama yaitu marker dan objek telah jadi. Setelah itu kita membuat aplikasi yang dapat membangkitkan objek dari marker yang dibuat dengan bantuan builder, untuk tugas akhir ini adalah dengan Adobe Flex SDK yang bersifat open source dan berbasis action script.

\section{Marker}

Marker merupakan perangkat keras lainnya yang digunakan untuk membuat suatu aplikasi Augmented Reality (AR), Marker merupakan sebuah persegi hitam dan ditengahnya terdapat persegi putih, marker putih yang ditengah bisa berbentuk gambar, angka, huruf atau apa saja, di dalam pola marker yang merupakan ilustrasi hitam dan putih persegi dengan batas hitam tebal dan latar belakang putih digunakan agar komputer mengenali posisi dan orientasi marker dan menciptakan dunia virtual $3 \mathrm{D}$ yaitu $(0,0,0)$ dan 3 sumbu yaitu X, Y, dan Z [4].

Penggunaan marker untuk aplikasi AR ini sudah lama dikembangkan sejak tahun 80an dan pada awal tahun 90an mulai dikembangkan untuk penggunaan Augmented Reality [4].

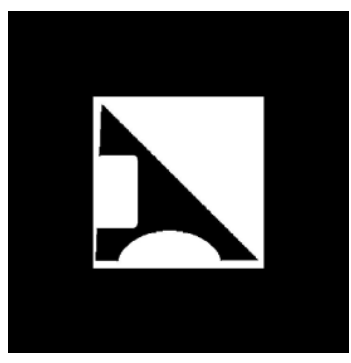

Gambar 1 Contoh Marker

\section{FlarToolKit}

FlarToolKit adalah tracking system library yang bersifat open-source sehingga memungkinkan programmer dengan mudah mengembangkan aplikasi Augmented Reality FlarToolKit merupakan porting (perubahan terhadap software untuk menjadikannya dapat digunakan di lingkungan yang berbeda) [4].
FlarToolKit hanya merupakan library untuk tracking pada AR, untuk menampilkan obyek 3D di lingkungan Flash, FlaRToolKit memerlukan sebuah library 3D yang didukung oleh flarToolKit adalah sebagai berikut :

- Alternativa3D

- Away3D

- Away3D Lite

- Papervision3D

Proses FlarToolKit secara garis besarnya sebagai berikut [3]:

1. Mengambil video dari webcam.

2. Binarisasi citra masukan (thresholding).

3. Memberi penanda (labelling).

4. Deteksi area persegi (Marker Outline Detection).

5. Pencocokan pola.

6. Me-render obyek 3D

\section{Papervision 3D}

Papervision3D adalah sebuah library yang ditulis dalam bahasa pemrograman as3 yang ditujukan untuk mengembangkan aplikasi Augmented Reality dengan menggabungkan computer vision based tracking libraries (seperti FlarToolkit, FlarManager dan Nyartoolkit) dengan 3D scene library (PV3D) seperti ditunjukkan pada gambar dibawah ini [5].

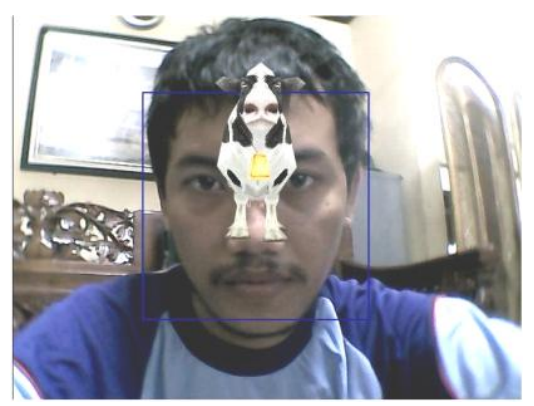

Gambar 2 Penambahan funsi Augmented Reality pada papervision 3D

\section{Adobe Flex}

ActionScript adalah bahasa pemrograman untuk Adobe Flash Player dan Adobe AIR run-time environment. Disini memungkinkan interaktivitas, 
penanganan data, dan banyak lagi di flash, flex, dan AIR pada konten dan aplikasi. ActionScript dilakukan oleh ActionScript virtual Machine (AVM), yang merupakan bagian dari Flash Player dan AIR. Aksi kode script biasanya dikompilasi ke format bytecode (semacam bahasa pemrograman yang ditulis dan dipahami oleh komputer) oleh kompilator, seperti yang dibangun ke dalam Adobe Flash CS3 Proffesional atau Adobe Flex Builder, atau yang tersedia dalam Adobe Flex SDK dan Flex layanan Data. Beberapa kunci ActionScript 3.0 meliputi [6] :

1. Sebuah baru ActionScript Virtual Machine, atau yang disebut AVM2, menggunakan satu bytecode instruksi baru dan menyediakan significant perbaikan kinerja

2. Sebuah basis kode kompiler yang lebih modern yang menganut standar (ECMA 262) ECMAScript dan yang melakukan optimasi lebih baik dari versi kompilator sebelumnya.

3. Sebuah antarmuka pemrograman aplikasi diperluas dan ditingkatkan (API), dengan kontrol obyek tingkat rendah dan berorientasi pada obyek model.

4. Sebuah inti bahasa berdasarkan ECMAScript (ECMA-262) edisi 4 draft spesifikasi bahasa.

\section{METODE PENELITIAN}

Pada bagian ini diuraian bahan yang digunakan dan cara kerja sistem dalam skenario game dalam pembuatan sistem Augmented Reality objek animasi menggunakan FlarToolKit.

\section{Parameter Penelitian}

Dalam membuat aplikasi ini, digunakan kamera yang cukup bagus untuk proses pengenalan marker agar aplikasi tersebut dapat berjalan dengan baik. Serta sebuah rancangan program yang baik agar dapat mengenali marker dengan cepat. sehingga objek animasi (game pingpong) dapat mudah ditampilkan dalam komputer.

\section{Prosedur Penelitian}

Secara sederhana Prosedur dalam penelitian ini dapat digambarkan dalam diagram sebagai berikut:

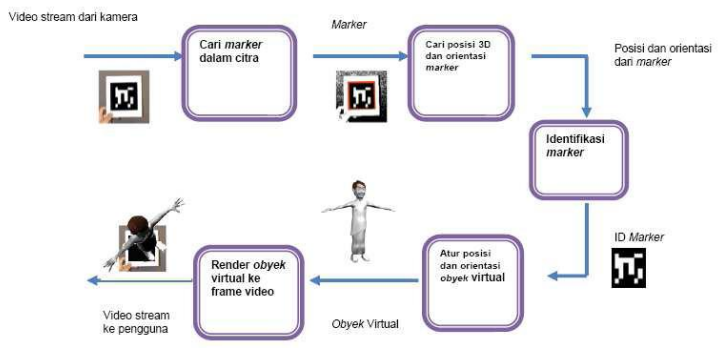

Gambar 3 Prosedur Penelitian [7]

\section{Deskripsi Sistem}

Sistem dirancang dengan menggunakan software Adobe Flash Bulider 4.5 dengan tambahan plugin FlarToolKit untuk Augmentednya, plugin papervision 3D sebagai obyeknya. Bahasa pemrograman yang digunakan adalah action script 3 dengan menggunakan konsep program berorientasi objek.

Aplikasi yang dibuat berupa animasi benda bergerak berbasis augmented reality dimana dalam hal ini langsung diterapkan ke dalam game pingpong. Dimana inti dari tugas akhir ini game pingpong dapat berinteraksi dengan augmented reality dan dalam menggerakkan setiap langkahnya menggunakan marker.

\section{Skenario Game}

Pada penelitian ini skenario disusun berdasarkan gerak boladari permainan pimpong. Gerak bola yang dimaksud disini adalah sebagai berikut :

1. Apabila bola menyentuh objek baik itu kambing ataupun monyet maka bola akan memantul

2. Apabila bola menyentuh lapangan sebelah kiri ataupun kanan maka bola akan memantul

3. Apabila bola menyentuh lapangan sebelah belakang dari salah satu objek baik itu kambing ataupun monyet maka objek yang bisa memasukkan ke 
belakang lapangan tersebut akan mendapatkan 1 poin

4. Apabila bola menyentuh halangan berupa objek tembok maka akan memantul

5. Apabila ada yang mendapatkan poin maka posisi awal bola akan kembali ke tengah lapangan diantara posisi lapangan 2 objek

6. Untuk objek yang digerakkan menggunakan marker dalam hal ini objek kambing apabila marker ditempatkan di lapangan lawan maka obyek tidak muncul

\section{Simulasi Game Pingpong}

Beberapa kondisi yang digunakan dalam simulasi ini adalah interaksi objek pada bola dan interaksi marker pada beberapa kondisi tertentu. Adapun kondisi tersebut adalah :

1. Bagaimana kondisi marker pada saat menampilkan objek dengan intensitas cahaya kecil (gelap).

2. Bagaimana kondisi marker pada saat menampilkan objek dengan intensitas cahaya sedang (menggunakan lampu).

3. Bagaimana kondisi marker pada saat menampilkan objek dengan intensitas cahaya besar (menggunakan cahaya matahari).

4. Bagaimana kondisi marker saat berada pada jarak terdekat

5. Bagaimana kondisi marker saat berada pada jarak terjauh

\section{HASIL DAN PEMBAHASAN}

Dalam bagian ini dibahas tentang hasil uji coba scenario yang telah dirancang oleh penulis. Uji coba dilakukan untuk mengetahui pengaruh intensitas cahaya pada Augmanted Reality objek animasi

\section{Kondisi Pada Intensitas Cahaya Kurang}

Kondisi ini merupakan kondisi dimana intensitas cahaya kurang (gelap) saat marker dihadapkan ke webcam. Hasil visualisasi kondisinya terlihat seperti gambar 4. berikut ini.

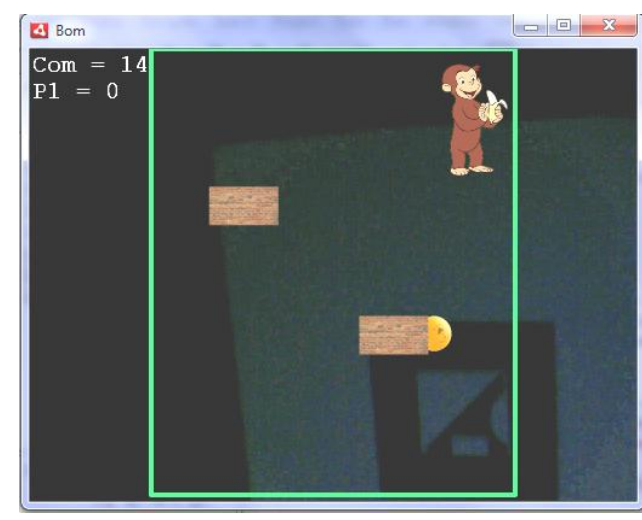

Gambar 4 Kondisi saat Intensitas Cahaya kecil (Gelap)

\section{Kondisi pada intensitas cahaya sedang}

Kondisi ini merupakan kondisi dimana intensitas cahaya sedang (menggunakan lampu) saat marker dihadapkan ke webcam. Visualisasi kondisinya terlihat seperti gambar 5. berikut ini.

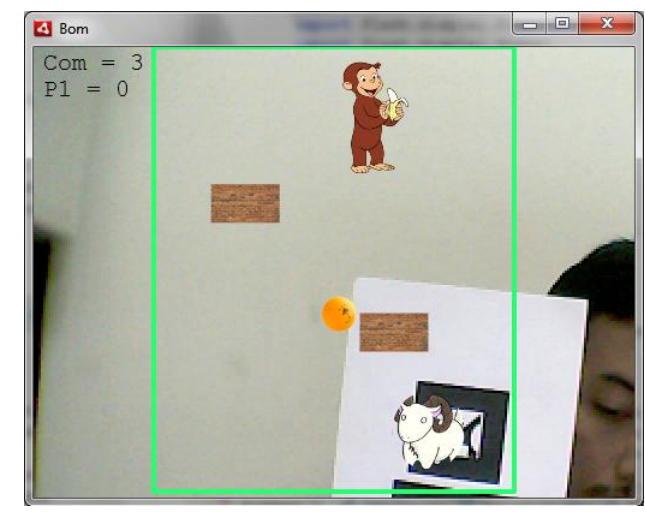

Gambar 5 Kondisi saat intensitas cahaya sedang (menggunakan lampu)

Kondisi pada intensitas cahaya besar

Kondisi ini merupakan kondisi dimana intensitas cahaya besar (menggunakan cahaya matahari) saat marker dihadapkan ke webcam. Visualisasi kondisinya terlihat seperti gambar 6 . berikut ini. 


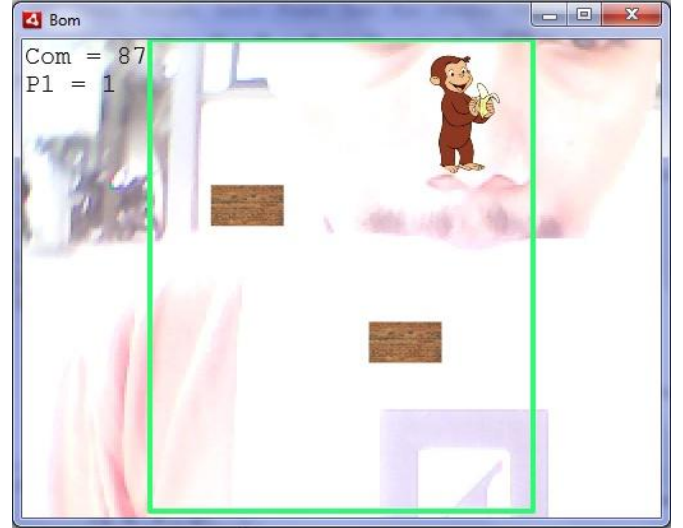

Gambar 6 Tampilan saat intensitas cahaya besar

\section{Kondisi pada intensitas jarak terdekat}

Kondisi ini merupakan kondisi dimana jarak terdekat saat marker dihadapkan ke webcam. Adapun jarak terdekat yang digunakan berjarak $10 \mathrm{~cm}$. Visualisasi kondisinya terlihat pada gambar 7 . berikut ini.

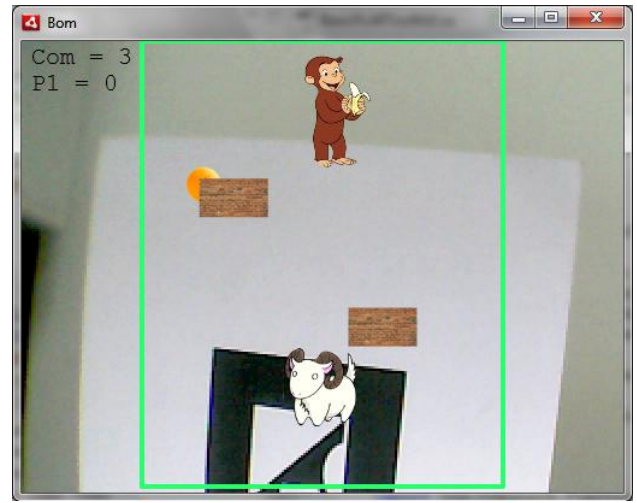

Gambar 7 Tampilan saat jarak terdekat

\section{Kondisi pada intensitas jarak terjauh}

Kondisi ini merupakan kondisi dimana jarak terjauh saat marker dihadapkan ke webcam. Visualisasi jarak terjauh yang digunakan berjarak 1 meter. Visualisasi kondisinya terlihat pada gambar 8 . berikut ini.

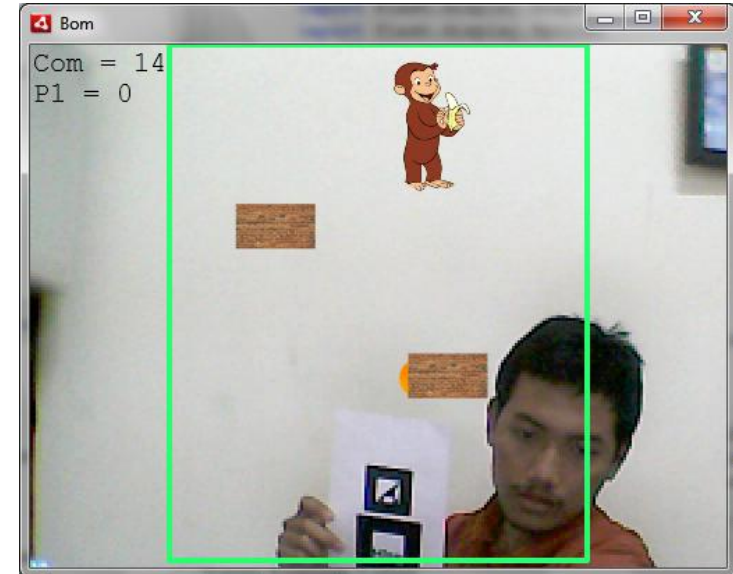

Gambar 8 Tampilan saat jarak terjauh

\section{Data Hasil Uji Coba}

Hasil uji coba simulasi dengan beberapa kondisi intensitas cahaya dan jarak, dapat dijelaskan pada tabel di bawah ini.

1. Berdasarkan intensitas cahaya

Tabel 1 Interaksi berdasarkan intensitas

\begin{tabular}{|c|c|c|c|}
\multicolumn{4}{c}{ cahaya } \\
\hline \multirow{2}{*}{ Marker } & \multicolumn{3}{|c|}{ Intensitas cahaya } \\
\cline { 2 - 4 } & Kecil & Sedang & Besar \\
\hline Objek & Tidak ada & Ada & Tidak ada \\
\hline
\end{tabular}

2. Berdasarkan jarak

Tabel 2 Interaksi berdasarkan Jarak

\begin{tabular}{|c|c|c|}
\hline \multirow{2}{*}{ Marker } & \multicolumn{2}{|c|}{ Jarak } \\
\cline { 2 - 3 } & $\begin{array}{c}\text { Terdekat } \\
(10 \mathrm{~cm})\end{array}$ & $\begin{array}{c}\text { Terjauh } \\
(1 \text { meter })\end{array}$ \\
\hline Objek & Ada & Tidak ada \\
\hline
\end{tabular}

Dari hasil uji coba dengan beberapa simulasi diatas, maka dapat diketahui bahwa pergerakan antar marker dipengaruhi oleh besarnya intensitas cahaya dan jarak.

Intensitas cahaya juga memiliki pengaruh sangat besar, yaitu apabila intensitas cahaya terlalu rendah marker tidak akan terbaca, begitu juga jika intensitas cahaya terlalu berlebih. Apabila sebagian marker tertutup oleh bayangan yang terlalu gelap objek pun tidak akan muncul. Jadi cahaya yang dibutuhkan kamera dalam menangkap marker dapat 
diatur sendiri sampai kira-kira cahaya mencukupi untuk menerangi daerah sekitar marker.

Jarak sangat berpengaruh dalam pembacaan marker. Jauh atau dekatnya marker dari kamera akan berpengaruh terhadap berjalannya program ini karena dengan jauhnya marker dari kamera webcam, maka kamera akan sulit mengenali marker tersebut, sehingga proses pembacaan marker tidak dapat berjalan dengan baik.

\section{KESIMPULAN}

Dari hasil pengujian dapat diambil kesimpulan bahwa:

1. Pembacaan marker oleh kamera sangat dipengaruhi oleh besarnya Intensitas cahaya. Untuk intensitas cahaya sedang (cahaya lampu) dapat menampilkan objek virtual. Sedangkan intensitas cahaya yang terlalu kecil (gelap) dan intensitas cahaya yang terlalu besar (cahaya matahari), objek virtual tidak terlihat.

2. Selain intensitas cahaya, jarak marker dengan kamera juga sangat berpengaruh dalam proses berjalannya sistem ini dimana marker yang telah dibaca oleh kamera ini nantinya akan di bandingkan dengan data marker yang menjadi acuannya. Bila terlalu dekat atau terlalu jauh maka kamera tidak dapat membaca marker dengan baik sehingga sistem tidak dapat mengenali marker tersebut. Jarak terdekat untuk marker terhadap kamera yang bisa menampilkan objek virtual adalah 10 $\mathrm{cm}$. Sedangkan jarak terjauh yang tidak bisa menampilkan objek adalah 1 meter.

Saran yang dapat disampaikan adalah: Objek pada game dapat diganti dengan objek 3D agar lebih menarik.

\section{DAFTAR PUSTAKA}

[1] Chafied, Muchammad. Asmara, Rengga S.Kom. dll., 2010, Brosur Interaktif Berbasis Augmented Reality. Surabaya : Teknik Informatika Politeknik Elektronika Negeri Surabaya.

[2] Azuma, Ronald T., 1997, A Survey of Augmented Reality. Presence : Teleoperators and Virtual Environment, vol. 6, no. 4, pp. 355385, 1997.

[3] Zulkarnaen, $\quad$ Rizky., 2010 , Perancangan Aplikasi Viewer Model $3 D$ Interaktif Berbasis Web dengan Teknologi Augmented Reality. Medan : Teknik Elektro Universitas Sumatera Utara.

[4] Choirul, Nurdika Ramadhan., Saleh, Akuwan S.ST., dll. 2011, Mobile Phone Augmented Reality Sebagai Model Pembelajaran. Surabaya : Teknik Telekomunikasi Politeknik Elektronika Negeri Surabaya.

[5] Ali, Mas Bahtiar., Saleh, Akuwan S.ST., dll. 2011, Sistem Augmented Reality Untuk Animasi Games Menggunakan Kamera pada PC. Surabaya : Teknik Telekomunikasi Politeknik Elektronika Negeri Surabaya.

[6] Cholifah, Chusnul., Ardilla, Fernando S.ST., dll. 2010, Rubber Ball - Virtual Game Dengan Menggunakan ARToolkit. Surabaya : Teknik Informatika Politeknik Elektronika Negeri Surabaya.

[7] Sutrisno Adam, Arie S. M. Lumenta, Jimmy R. Robot Implementasi Teknologi Augmented Reality pada Agen Penjualan Rumah, E-journal Teknik Elektro dan Komputer (2014), ISSN 2301-8402, 